\title{
Breath Alcohol Concentration in Japanese Breast Cancer Patients Following Alcohol-Containing Chemotherapeutic Agent Infusion
}

\author{
Naoko Itoi ${ }^{1,2}$, Hajime Abe ${ }^{2,3^{\star}}$, Tsuyoshi Mori ${ }^{2}$, Yuki Kawai $^{2}$, Yoshihiro Kubota $^{2}$, Tomoko Umeda $^{2}$ and Tohru Tani ${ }^{4}$ \\ ${ }^{1}$ Department of Surgery, Hino Memorial Hospital, Japan \\ ${ }^{2}$ Division of Breast and General Surgery, Shiga University of Medical Science Hospital, Japan \\ ${ }^{3}$ Breast Center, Bell Land General Hospital, Japan \\ ${ }^{4}$ Department of Surgery, Shiga University of Medical Science, Japan
}

"Corresponding author: Hajime Abe, M.D., Ph.D., Breast Center, Bell Land General Hospital, 500-3 Higashiyama, Naka-ku, Sakai, Osaka 599-8247, Japan, Tel: +81-72-234-2001; Fax: +81-72-234-2003; E-mail: abe@belle.shiga-med.ac.jp

Received date: July 07, 2014, Accepted date: July 22, 2014, Published date: July 29, 2014

Copyright: ( 2014 Itoi N, et al. This is an open-access article distributed under the terms of the Creative Commons Attribution License, which permits unrestricted use, distribution, and reproduction in any medium, provided the original author and source are credited.

\begin{abstract}
Background: Preparations containing dehydrated ethanol as an additive, due to its water-insoluble properties, have been frequently used for chemotherapeutic agents, such as paclitaxel (PTX), docetaxel (DOC) and eribulin. When selecting these drugs, the influence of alcohol on the central nervous system (CNS) must be considered. In this study, we measured the breath alcohol concentration (BAC) in Japanese breast cancer patients treated with these agents.
\end{abstract}

Method: Japanese patients with breast cancer receiving outpatient chemotherapy with alcohol-containing agents were registered. The BAC was measured immediately after drip infusion and 30 and 60 minutes later.

Result: Thirty-one female patients were enrolled in this study. Breath alcohol was detected in 18 patients (58\%) immediately after administration: 6 patients (75\%) with PTX, $10(50 \%)$ with DOC and 2 (67\%) with eribulin. After 30 minutes, no patient had BAC over $0.15 \mathrm{mg} / \mathrm{L}$, but breath alcohol under $0.1 \mathrm{mg} / \mathrm{L}$ was detected in 1 patient with PTX and 1 with DOC after 60 minutes.

Conclusion: The influence of alcohol may disappear 60 minutes or more after administration, making it possible to travel home safely at this time.

Keywords: Breast Cancer; Breath; Alcohol concentration; Chemotherapy

\section{Abbreviations}

PTX: Paclitaxel; DOC: Docetaxel; CNS: Central Nervous System; BAC: Breath Alcohol Concentration; ADH: Alcohol Dehydrogenase; ALDH: Aldehyde Dehydrogenase

\section{Introduction}

Breast cancer is the most common cancer in women. The incidence of death due to breast cancer has declined in the USA and Europe, mostly owing to improved detection and treatment [1]. Breast cancer has been treated with endocrine therapeutic drugs including tamoxifen and aromatase inhibitors, or chemotherapeutic agents including anthracyclines, antimetabolites, taxanes and eribulin [2-5]. Anthracyclines and taxanes (paclitaxel (PTX) and docetaxel (DOC)) are commonly used for the first-line treatment of breast cancer, while eribulin is used for second- or third-line treatment. In particular, preparations containing dehydrated ethanol as an additive, due to its water-insoluble properties, have been frequently used for chemotherapeutic agents such as PTX, DOC and eribulin. When selecting these drugs, the influence of alcohol on the central nervous system (CNS) must be considered. The potential for blood and breast alcohol levels to exceed the legal sobriety limit for driving must also be considered if alcohol-containing chemotherapeutic agents are given to outpatients. It is also important to consider the possible CNSdepressant actions of the alcohol contained in drug formulations. In this study, we measured the breath alcohol concentration (BAC) in Japanese breast cancer patients treated with alcohol-containing chemotherapeutic agents, and evaluated it according to the definition of driving under the influence of alcohol (BAC: $0.15 \mathrm{mg} / \mathrm{L}$ or more) to examine the safety of alcohol-containing chemotherapeutic agent administration at an outpatient clinic.

\section{Patients and Methods}

In the study, Japanese patients with breast cancer were registered. All patients were over 18 years, had an Eastern Cooperative Oncology Group Performance Status of 0 to 1 , were receiving outpatient chemotherapy with alcohol-containing agents, had signed an informed consent form and had no history of alcoholism. Patients were excluded from this study if they had serious underlying diseases, a history of severe hypersensitivity to the drug to be administered, were pregnant or lactating, or based on the decision of the attending physician. As chemotherapy regimens, $80 \mathrm{mg} / \mathrm{m}^{2}$ weekly PTX; 100,75 and $60 \mathrm{mg} / \mathrm{m}^{2}$ triweekly DOC; and $1.4 \mathrm{mg} / \mathrm{m}^{2}$ eribulin were used. PTX was administered over 60 minutes, DOC over 60 minutes and eribulin over 5 minutes. 
Citation: Itoi N, Abe H, Mori T, Kawai Y, Kubota Y, et al. (2014) Breath Alcohol Concentration in Japanese Breast Cancer Patients Following Alcohol-Containing Chemotherapeutic Agent Infusion. J Pharmacovigilance 2: 138. doi:10.4172/2329-6887.1000138

Page 2 of 4

The patients were instructed to breathe on a measuring instrument for 4 seconds. The BAC was measured immediately after drip infusion and 30 and 60 minutes later (total: 3 times). We used an SOCIAC-X SC-202 instrument (Figure 1) for measuring the concentration of alcohol (Central Automotive Products, Ltd., Osaka, Japan).

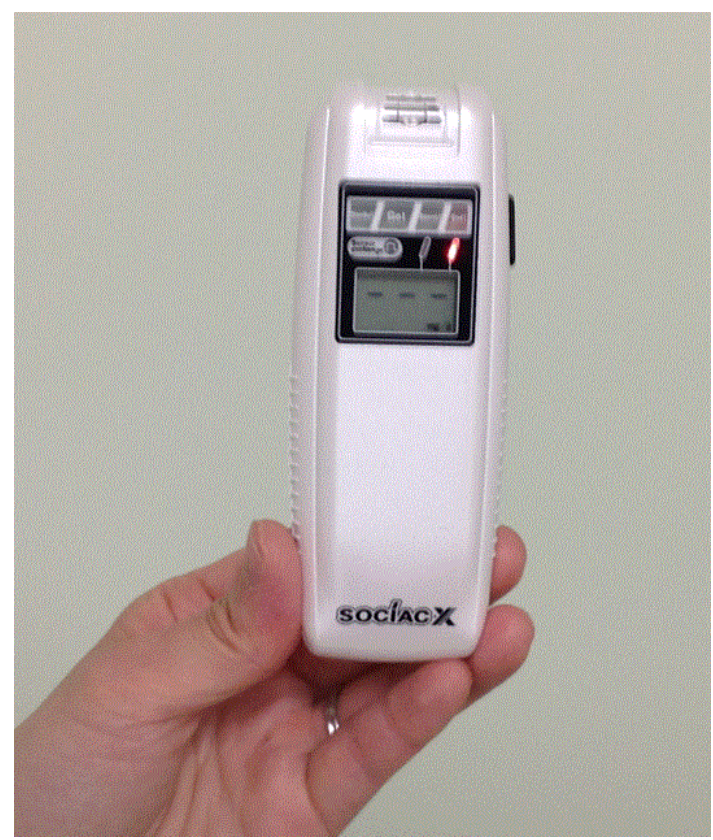

Figure 1: SOCIAC-X SC-202 instrument.

Prior to this study, the protocol was approved by the Institutional Ethics Review Board of Shiga University of Medical Science.

\section{Results}

\section{Patients' characteristics}

From April 2012 to March 2013, 31 patients were enrolled in this study. Their ages ranged from 29 to 75 years, with a median of 56 years. All patients were female. They were selected for preoperative chemotherapy in 6 patients, for postoperative chemotherapy in 12 and for relapse treatment in 13 . Eight patients received weekly PTX and 3 patients received eribulin. As the DOC regimen, $100 \mathrm{mg} / \mathrm{m}^{2}$ DOC was administered to 5 patients, $75 \mathrm{mg} / \mathrm{m}^{2}$ to 13 and $60 \mathrm{mg} / \mathrm{m}^{2}$ to 2 (Table 1). After chemotherapy administration, there were no alcohol-related hot flushes or drunkenness-like symptoms.

\section{BAC}

Breath alcohol was detected in 18 patients (58\%) immediately after administration: 6 patients (75\%) with PTX, 10 (50\%) with DOC and 2 (67\%) with eribulin (Figures 2-4). The BAC was $0.15 \mathrm{mg} / \mathrm{L}$ or more in 1 patient with PTX and 1 with DOC. After 30 minutes, there were no patients with BAC over $0.15 \mathrm{mg} / \mathrm{L}$, but breath alcohol under $0.1 \mathrm{mg} / \mathrm{L}$ was detected in 1 patient with PTX and 1 with DOC after 60 minutes. With respect to the dose of DOC, in the $100 \mathrm{mg} / \mathrm{m}^{2}$ group, breath alcohol was detected in 4 patients $(80 \%)$ immediately after administration and in 6 patients $(46 \%)$ in the $75 \mathrm{mg} / \mathrm{m}^{2}$ group, but it was not detected in the $60 \mathrm{mg} / \mathrm{m}^{2}$ group.

\begin{tabular}{|l|l|}
\hline Age (median) & $29-75(46)$ \\
\hline Gender & \\
\hline Female : Male & $31: 0$ \\
\hline Treatment & \\
\hline Neoadjuvant & 6 \\
Adjuvant & 12 \\
Metastatic & 13 \\
\hline Regimen & \\
\hline PTX & 8 \\
DOC 100 & 5 \\
75 & 13 \\
60 & 2 \\
Eribulin $\left(\mathrm{mg} / \mathrm{m}^{2}\right)$ & 3 \\
\hline
\end{tabular}

Table 1: Patients characteristics. (Note: PTX: Paclitaxel; DOC: Docetaxel)

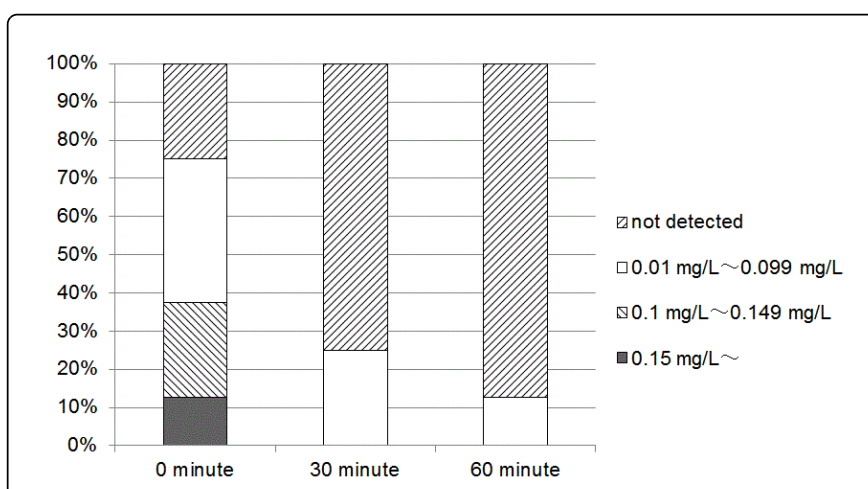

Figure 2: Breath alcohol concentration of PTX. (Note: PTX: paclitaxel)

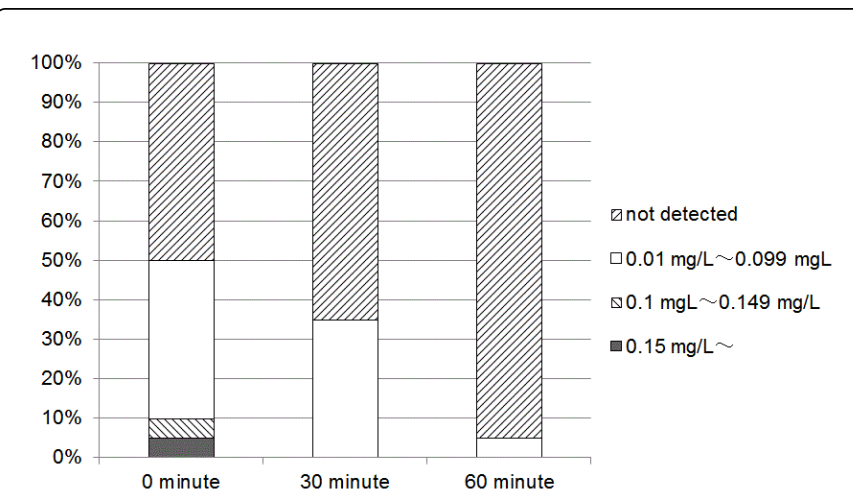

Figure 3: Breath alcohol concentration of DOC. (Note: DOC: docetaxel) 


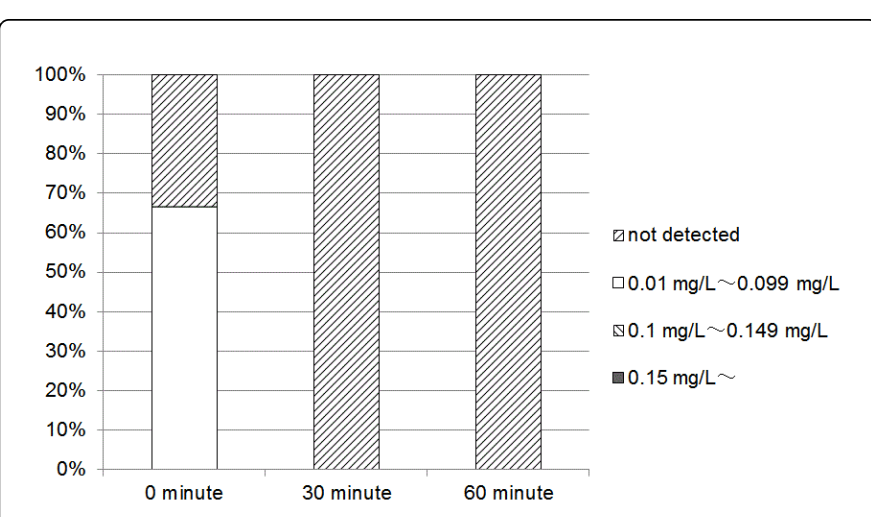

Figure 4: Breath alcohol concentration of eribulin.

\section{Discussion}

More than $90 \%$ of alcohol is metabolized in the liver, and 2 to $10 \%$ is excreted in breath/urine/sweat [6]. Concerning alcohol metabolism, alcohol resistance more frequently appears in Mongoloids including Japanese due to differences in alcohol dehydrogenase (ADH) and aldehyde dehydrogenase (ALDH) activities [6]. Thus, Japanese people are less tolerant to alcohol than Caucasians. In addition, females tend to show higher blood alcohol concentration than males [7]. In recent years, outpatient chemotherapy has increased patient quality of life and improved medical costs. In addition, as a result of increasing outpatient chemotherapy, more patients drive themselves to hospital for chemotherapy.

Antimicrotubule agents such as PTX, DOC and eribulin act by inducing apoptosis in cancer cells via mitotic arrest after tubulin binding; PTX and DOC inhibit microtubule shortening [8], whereas eribulin prevents microtubule growth [9]. These agents are not soluble in water, so the attached solvent contains dehydrated ethanol. One hundred mg of PTX is combined with $8.33 \mathrm{ml}$ of ethanol, $80 \mathrm{mg}$ of DOC with $1.58 \mathrm{ml}$ and $1 \mathrm{mg}$ of eribulin with $0.1 \mathrm{ml}$. In this study, the doses of PTX and eribulin were $80 \mathrm{mg} / \mathrm{m}^{2}$ and $1.4 \mathrm{mg} / \mathrm{m}^{2}$, respectively. The dose of DOC was 60 to $100 \mathrm{mg} / \mathrm{m}^{2}$. These doses of the agents were associated with $0.22 \mathrm{~g}$ to $10.6 \mathrm{~g}$ of ethanol, which is equivalent to $4 \mathrm{ml}$ to $210 \mathrm{ml}$ of $5 \%$ beer. This prompted us to consider the influence of this alcohol on the CNS.

There is a greater risk of intoxication leading to car accidents in patients with poor alcohol metabolism. In the Road Traffic Act in Japan, BAC that constitutes drunk driving is $0.15 \mathrm{mg} / \mathrm{L}$, and the venous alcohol concentration is $0.3 \mathrm{mg} / \mathrm{mL}$. The ratio of venous alcohol concentration to exhaled BAC is approximately 2300:1 [10]. Moreover, the depressant effect of alcohol on the CNS is increased by concurrent intake of antihistamines, resulting in greater impairment of motor performance [11]. In this study, breath alcohol was detected immediately after administration in $18(58 \%)$ of 31 breast cancer patients. However, no patient complained of hot flushes or drunkenness-like symptoms. Only 2 patients (6\%) fulfilled the definition of being under the influence of alcohol, if they had been driving. After 30 minutes, the BAC levels were below the regulated limit for driving. After 60 minutes, they were below the detection limit, except in 2 patients. Some studies reported that there was a relationship between the infusion speed and BAC [12,13], whereas others indicated that there was no relationship [14]. In our study of DOC, there was a correlation between the infusion speed and BAC.

On the basis of these results, it may be possible to drive a car after an interval of more than 60 minutes following the administration of an alcohol-containing agent. However, there are individual differences in $\mathrm{ADH}$ and ALDH isozymes. In addition, drug-induced symptoms such as nausea/vomiting may occur; therefore, driving after drug administration should be avoided.

\section{Acknowledgments}

We thank all the patients who participated in this study.

\section{Conflict of Interest}

The authors declare no conflict of interest.

\section{References}

1. Jemal A Bray F, Center MM, Ferlay J, Ward E, et al. (2011) Global cancer statistics. CA Cancer J Clin 61: 69-90.

2. Fisher B Jeong JH, Anderson S, Wolmark N (2004) Treatment of axillary lymph node-negative, estrogen receptor-negative breast cancer: updated findings from National Surgical Adjuvant Breast and Bowel Project clinical trials. J Natl Cancer Inst 96: 1823-1831.

3. Roché H, Fumoleau P, Spielmann M, Canon JL, Delozier T, et al. (2006) Sequential adjuvant epirubicin-based and docetaxel chemotherapy for node-positive breast cancer patients: the FNCLCC PACS 01 trial. J Clin Oncol 24: 5664-5671.

4. Martin M Pienkowski T, Mackey J, Pawlicki M, Guastalla JP, et al. (2005) Adjuvant docetaxel for node-positive breast cancer. N Engl J Med 352: 2302-2313.

5. Cortes J O'Shaughnessy J, Loesch D, Blum JL, Vahdat LT, et al. (2011) Eribulin monotherapy versus treatment of physician's choice in patients with metastatic breast cancer (EMBRACE): a phase 3 open-label randomised study. Lancet 377: 914-923.

6. Harada S, Misawa S, Agarwal DP, Goedde HW (1980) Liver alcohol dehydrogenase and aldehyde dehydrogenase in the Japanese: isozyme variation and its possible role in alcohol intoxication. Am J Hum Genet 32: 8-15.

7. Becker U Deis A, Sørensen TI, Grønbaek M, Borch-Johnsen K, et al. (1996) Prediction of risk of liver disease by alcohol intake, sex, and age: a prospective population study. Hepatology 23: 1025-1029.

8. Aftimos P Awada A (2011) Survival benefit of eribulin mesylate in heavily pretreated metastatic breast cancer: what next? Adv Ther 28: 973-985.

9. Jordan MA Kamath K, Manna T, Okouneva T, Miller HP, et al. (2005) The primary antimitotic mechanism of action of the synthetic halichondrin E7389 is suppression of microtubule growth. Mol Cancer Ther 4: 1086-1095.

10. Jones AW (1985) Electrochemical measurement of breath-alcohol concentration: precision and accuracy in relation to blood levels. Clin Chim Acta 146: 175-183.

11. Webster LK Crinis NA, Morton CG, Millward MJ (1996) Plasma alcohol concentrations in patients following paclitaxel infusion. Cancer Chemother Pharmacol 37: 499-501.

12. Taniguchi R Henmi N, Hirata R, Tada T, Sato Y, et al. (2010) [Investigation of factors associated with time change in breath alcohol concentration after paclitaxel administration]. Gan To Kagaku Ryoho 37: 1313-1316.

13. Ban A, Oshima Y, Hisada T, Gocho S, Ishikawa M, et al. (2009) The Effects of Alcohol Contained in Paclitaxel on patients. J Jpn Soc Hosp Pharm 45: 1123-1126. 
Citation: Itoi N, Abe H, Mori T, Kawai Y, Kubota Y, et al. (2014) Breath Alcohol Concentration in Japanese Breast Cancer Patients Following Alcohol-Containing Chemotherapeutic Agent Infusion. J Pharmacovigilance 2: 138. doi:10.4172/2329-6887.1000138

Page 4 of 4

14. Komagata H Yoneda S, Sakai H, Isobe K, Shirai T, et al. (2005) Breath alcohol concentrations in Japanese outpatients following paclitaxel and docetaxel infusion. Int J Clin Pharmacol Res 25: 195-202. 